\title{
Corrigendum
}

\section{Reevaluation of vitamin E supplementation of dairy cows: bioavailability, animal health and milk quality - CORRIGENDUM}

\section{Politis}

First published online 21 March 2012

doi:10.1017/S1751731112000225, published by Cambridge University Press, 21 February 2012

In Figure 2 of the article by Politis (2012), presented in Animal, an error inadvertently appears in the second ring of all molecules; instead of a hexane ring, a heptane ring is presented. The correct version (hexane ring) of Figure 2 is shown below. The author apologises for any confusion caused.

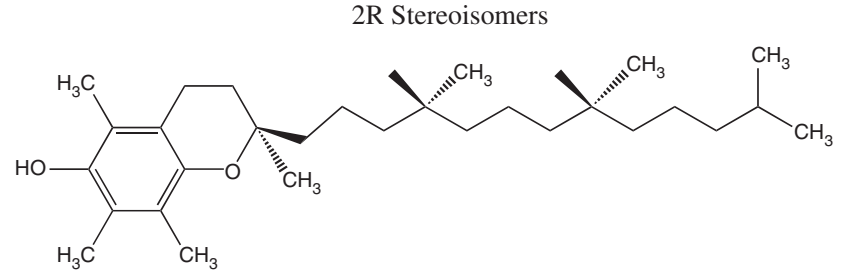

RRR
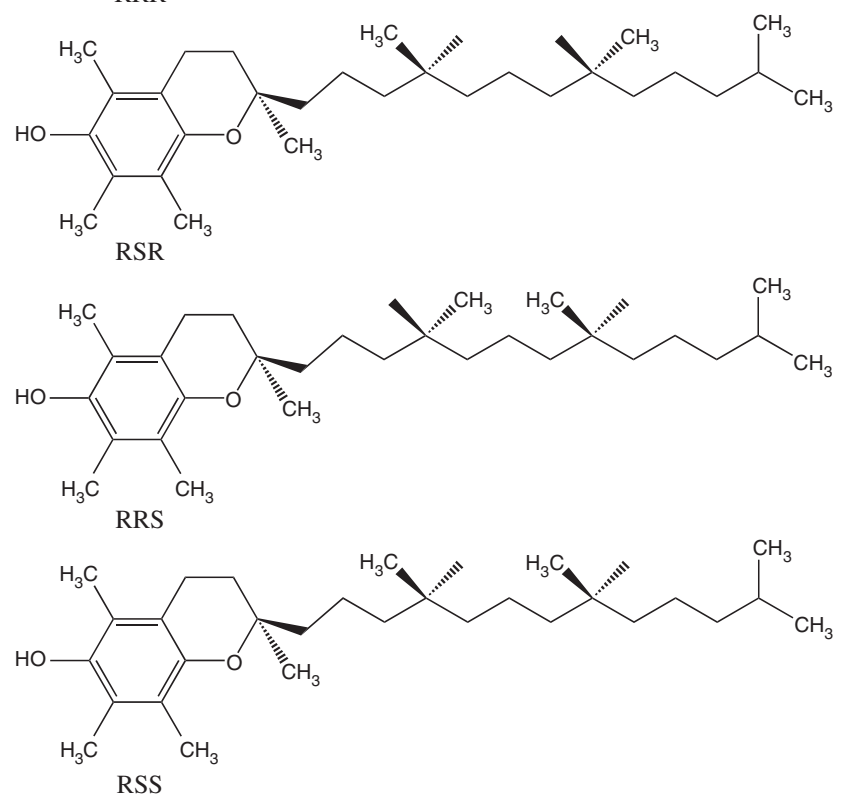

2S Stereoisomers

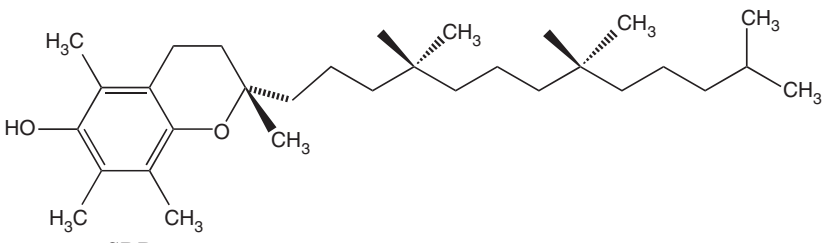

SRR
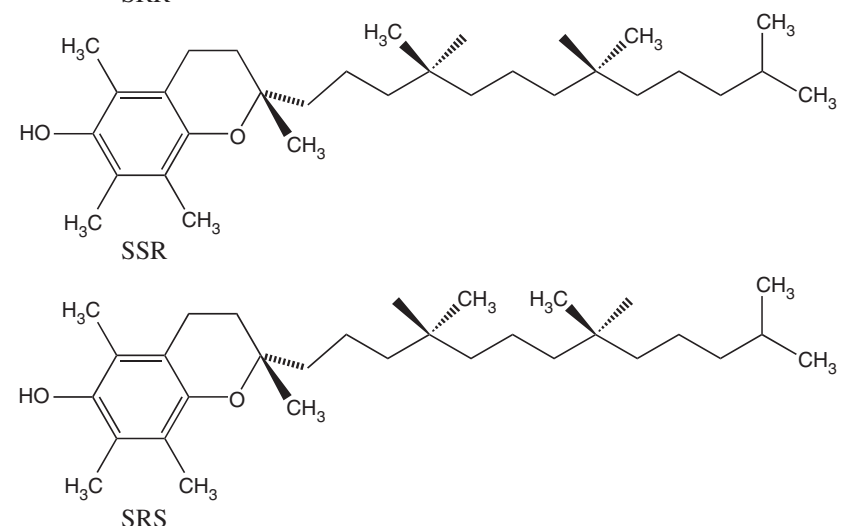

SRS

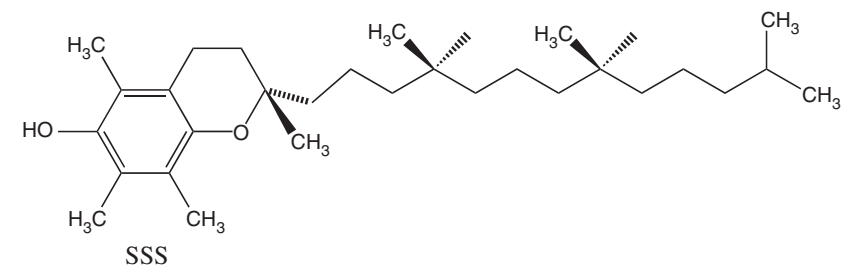

Figure 2 Diagrammatic representation of various stereoisomers of $\alpha$-tocopherol.

\section{Reference}

Politis I 2012. Reevaluation of vitamin E supplementation of dairy cows: bioavailability, animal health and milk quality. Animal; doi:10.1017/S1751731112000225. Published by Cambridge University Press, 21 February 2012. 